\title{
Training Strategy of Tourism Performing Art Talents in Higher Vocational Colleges under the Integration of Culture and Tourism
}

\author{
Li Qing,"*, Li Jia ${ }^{2}$ \\ ${ }^{1}$ Shanxi Vocational College of Art, Shanxi, China; Krirk University, Thailand \\ ${ }^{2}$ College of Music, Shanxi Normal University, Taiyuan, Shanxi, China \\ *Corresponding author:Li Qing
}

Keywords: Integration of Culture and Tourism, Tourism Performing Art, Talent Training

\begin{abstract}
Culture brings a great power for national survival and development. Tourism, as a kind of cultural exchange, has made the development of tourism industry and the aesthetic needs of tourists no longer stay in the level of static landscape experience like appreciating scenery. However, performance arts in tourism activities have quietly become an important way for tourists to enjoy local culture with the in-depth development of tourism activities. At the same time, more and more human geographies, human customs and other local famous stories will be mined and created by tourism attractions into tourism performing art products, so as to make tourists feel the local cultural atmosphere and the local customs. Higher vocational colleges, as an important part of national higher education, play a crucial role in cultivating skilled and practical talents. While the integrated development of culture and tourism industry makes tourism performing art products "open up" a new development path for the talent training mode of higher vocational education. The in-depth cooperation between schools and enterprises is carried out to connect with the industry, effectively integrating these three resources. It provides a strong guarantee for the effective supply of tourism performing art talents and the improvement of the fit between talent training and social needs through the construction of a new talent training system for vocational education integrating "characteristic curriculum system, excellent teachers, stage and social testing process".
\end{abstract}

\section{Introduction}

Tourism is a kind of cultural exchange, and tourism performing art has become a hot topic in recent years. The most obvious result of the integration of culture and tourism is economic benefits. The emergence of tourism performing art products constitutes a distinct symbol of tourism industrialization. Pan Tian's Industrialization of China's Tourism Performing Arts believes that tourism performing arts is a commodity because of its characteristics of commodities, which not only means a labor product, but also can be used for exchange (Pan, 2018). From the perspective of creation, planning and management, tourism performing art products are the fruits of people's labor, while the use value of them depends on tourism and performance, so that tourists and audiences can 
meet their inner expectations as well as the material and cultural needs. It indicates that tourism products mainly appear in the form of performing arts. What can meet the tourism and cultural needs of buyers, participants and audiences are the performing arts that expressing the local cultural connotation through creation and production. Only in this way can it produce obvious economic benefits.

\section{Tourism Performing Art}

\subsection{Concept of Tourism Performing Art}

Liang Yongkang and Zheng Xiangmin propose the concept of tourism performing art in the study On Operation Safety Guarantee System of Large-scale Live Tourism Performing Art Projects, which refers to a variety of cultural and artistic performance activities carried out by cultural tourism performance in various performance places in the tourist area, so as to attract tourists by expressing the cultural characteristics of the region. Briefly, cultural tourism performance is the connection between performing art programs and tourism activities with cultural characteristics in the form of performing arts on a specific stage, so as to attract tourists with the promotion of their tourism consumption (Liang, 2012). The concept of tourism performing art held in this paper is the various cultural and artistic performance activities shown by cultural tourism performance in different performance places in the tourist area, which attracts tourists with the cultural characteristics of the region.

Relying on the cultural resources of local tourism areas, tourism performing art is a themed commercial performance activity that creatively expresses the local customs, mountains, landscapes and national characteristics in a specific area through various performance forms like song, dance, music, drama and Quyi (Quan, 2018). It is displayed in the tourist site in a dynamic artistic form, so that tourists can fully get in the cultural atmosphere and artistic experience exchange of the tourist site in the experience of artistic works. The forms of performance products include various activities such as dance, drama and music. Cultural tourism performing arts can promote the tourism consumption through attracting tourists, which can be concluded that tourism performing art has the distinctive characteristics of promoting the local cultural characteristics, the combination of tourists' appreciation and participation, and the commercial economy. Based on solid market foundation, tourism performing art has brought new opportunities to the tourism industry with diverse forms of expression and rich spiritual experience, while the level of tourism performing arts is closely related to tourism performing art talents. The concept of "good works" is based on both artistic production and the organizational form of labor. A good work can shorten the distance between performance creators and tourism recipients with the characteristics of authenticity, making art works accepted and recognized, so as to make art more prosperous.

\subsection{Tourism performing art talents}

Talent training refers to a process of education and learning for natural persons, and the chosen one generally should be trained and studied in order to become professionals required by all industries. Talent training is closely related to relevant national policies, which play a regulatory role in industrial development. Accordingly, talent training will also promote industrial development and redevelopment. In another words, talent factor is the most important regulatory driving force for the redevelopment of tourism performing arts industry ( $\mathrm{Li}, 2019)$.

There are two meanings in performing arts: the first is the performing arts such as drama, song, dance and acrobatics, and the second is performing skills (Baidu Encyclopedia, 2021). Tourism performing art talents include staff related to art creation talents, art planning talents, art performing 
talents and art education talents. The main factor affecting the long-term vitality of tourism products is the cultural connotation of tourism performing art works. Tourism performing art is an important carrier in scenic spots, and tourism performing art talents can lead the performance works. Tourism performing art talents need to select the part with the most local characteristics from the vast ocean of local culture to interpret in a modern aesthetic artistic way by rich artistic expressions, creating tourism performing arts infectivity and attraction.

\subsection{Current Situation of Tourism Performing Art Talents}

In terms of today's tourism professionals in China's universities, most of tourism disciplines are probably hotel management, tourism management, tourism landscape design, etc. At present, there is only about the training of management talents on tourism performing art in China, without major known as tourism performing arts. As a matter of fact, the tourism performing art industry is a very urgent to compound talents, so talent training must be multi-functional. The lack of compound talents in the tourism performing art market will bring an unsustainable development trend to the industry. Nowadays, many people who work on the tourism performing art turn to this industry because of the needs of the market. They do not necessarily have a deep understanding of the industry, resulting in a waste of human resources in tourism performing art enterprises. Some people only understand the tourism performing art management or the vocal and dance performances in the industry, directly causing the lack of consumer experience and low evaluation of tourism performing art products, which has a direct impact on driving the regional economy.

\section{Training of Tourism Performing Art Talents}

The training of tourism performing art talents has become the point focused by the industry in the development of cultural and tourism integration in recent five years, enhancing the supporting role of tourism performing art talents efficiency and talent training in economic development.

\subsection{Adjustment of Teaching Curriculum System and Construction of Curriculum Resources}

The cultural connotation of performing art products is the core strength of tourism performing art products to avoid the same content and form. It will be eliminated by the market without characteristic culture, which needs professional talents for excavation and planning. Curriculum is the first stage to realize the training of tourism performing art talents, the structure of which is the primary path to implement this talent training goal. A curriculum system that highlights the requirements of job ability and the characteristics reflected by the combination of culture and tourism is needed, so as to realize the accurate connection between the professional standards of industry enterprises and the curriculum content. It is also the ultimate goal of higher vocational talent training.

From the perspective of curriculum structure, the unity and diversity of knowledge in classroom should be taken as the basic principle. For example, dance history should be covered in compulsory courses, and relevant contents should be specially designed according to the order training contract of each class. In dance appreciation courses, some content adjustments should also be carried out according to the classes ordered by different tourist attractions. In terms of the professional skill courses, courses such as speech and eloquence, drama performance and basic vocal music can be opened according to the multi-directional needs of the cultural market and the talents trained with the orders of tourist attractions, especially the specific performance content of each tourist attraction should be directly implanted into the classroom. Based on such course adjustment, it is an opportunity to update the college's teaching resource database, which should cover the plays of 
national excellent tourist attractions more than the performance plays of tourist attractions in the province, so as to enhance the market competitiveness of tourism performing art talents.

\subsection{Enriching and Constructing Faculty}

The increasingly competitive industry environment of tourism and the high demand for tourism performing arts talents not only increase employment opportunities for the industry, but also force the field of education and teachers engaged in education. At present, the integrated development of culture and tourism is necessary, but there are really few professional teachers who are skilled in both cultural tourism professional knowledge and tourism performing art. The improvement of teachers' quality construction is the primary task in the important link of talents training of cultural and tourism products. The comprehensive quality of teachers can directly affect students.

Teachers' professional knowledge reserve and professional quality determine the professional quality of students to a certain extent. Thus, high-quality and capable students can only be trained by high-level teachers. In higher vocational colleges, the traditional teaching pays more attention to skills than theory. In today's fierce competition for tourism performing art talents, the traditional teaching content is no longer enough. Therefore, it is important for teachers to timely supply knowledge and skills related to the tourism industry. It requires teachers to make use of various learning opportunities and major media network platforms to strengthen their self-cultivation, especially the well-known figures in the industry can be invited to teach and train in person. Teachers should pay attention to the construction of professional ethics more than learning industry knowledge. The noble morality like self-discipline, honesty, reliability, the profound professional quality and the professional knowledge structure will certainly develop the tourism performing art talents with high-quality and high-standard.

\subsection{Process of Stage Practice and Social Examination}

The stage practice refers to the training of students' performance and creative ability. From the perspective of stage practice, schools and cooperative enterprises should actively provide art stages for different tourist attractions, encouraging students to actively participate. Besides, the cultural knowledge and professional skills learned in the school should be turned into the driving force to promote artistic practice, stimulating students' enthusiasm to perform and create twice through tourism performing art plays. Finally, in the process of stage practice, reflection on their professional ability should be carried out to promote their growth through the re-examination.

The social examination is a test that inspects the effectiveness of the performing art talents training, which means that the school should train by putting them into the tourist attractions for post practice to accept the market test, so as to realize the targeted test and training of their professional ability, communication ability and ability to solve performance problems. With this mode of training, students can complete the training target of applied talents in higher vocational education in a short three years.

\section{Strategies for Improving Ability of Tourism Performing Art Talents (Taking Shanxi Vocational College of Art as Example)}

\subsection{Improve Comprehensive Quality of Tourism Performing Art Talents}

On the one hand, it should "go out" to input fresh blood for Shanxi talent team. The universities cooperation, the order-type talent training cooperation agreements with major tourist attractions, and the practice and training in tourist attractions in Shanxi with the university tourism practice 
platform should all be carried out to provide talent support and assistance for the development of tourism in Shanxi Province. On the other hand, it should "strengthen quality" to improve the quality of "craftsman" in tourism talent team. Tourism performing art talents skill competition can be organized to achieve the result that competition promotes teaching. The training courses of improving the comprehensive quality of tourism performing art talents can be held to strengthen exchange and learning. A group of tourism talents with good professional ethics, excellent professional knowledge and high service level, which can promote the overall improvement of service quality of tourism performing art practitioners in Shanxi can be selected.

\subsection{Strengthen Tripartite Cooperation among Schools, Enterprises and Industries}

A joint education team of the university, enterprises and industries can be established based on the college itself. It can cooperate with the leading enterprises in the domestic tourism industry with the advantages of the college's teaching resources, and carry out the long-term cooperation with the local tourism enterprises at the same time (scenic spots like Wutai Mountain in Xinzhou, Yungang Grottoes in Datong, Dahuaishu in Hongtong, etc.) to encourage enterprises to participate in the education and development of tourism service talents. For example, teachers can have the opportunity for temporary training in enterprises, and students can have the opportunity for practical exchange and learning through the cooperation between school and enterprise, which can meet the specific needs of tourism enterprises for talents' ability and quality under the current condition of personally understanding culture-tourism integration. In addition, it can provide opportunities of post practice for tourism performing art talents, which is the foundation for tourism enterprises to recruit skilled talents in line with professional needs. Excellent experts in the tourism industry all over the country can be invited to proofread teachers, students and recruit people engaged in the tourism performing art industry to exchange with "sit-in" guidance. Teaching resources can be jointly developed by schools, enterprises and industries to establish a national teaching resource database of classic plays in tourist attractions, so as to enrich the training methods of tourism performing art talents.

\subsection{Understand Service Society and Enhance Self-worth}

Tourism performing art has the dual characteristics of spiritual and cultural products as well as the tourism attraction, which directly produces two benefits - social benefits and economic benefits. regardless of social benefits or economic benefits, it determines that the development of tourism performing art projects must pay attention to the spiritual realm and cultural level, with the resonation with the people. At the same time, it plays a role in promoting the dynamic development, inheritance and popularization of local traditional culture. A number of excellent works with profound heritage, distinctive characteristics and educative content, such as tourism performing art works with exquisite art, profound thought and excellent creation, should be launched industriously. Give life to the works to deeply explore the cultural soul essence, traditional Chinese virtues and humanistic spirit of Chinese excellent traditional culture, contemporarily expressing with rich and colorful art forms. In this process, by means of participating in the whole process of tourism performing art works, you can learn to analyze yourself with full understanding about yourself, so as to find and solve problems to spur yourself, obtaining the recognition of tourists, colleagues, teachers and classmates, in other words, realizing self-worth. Self-worth has no end, only with perseverance, the embodiment of which is to truly obtain social recognition.

In the future training of tourism performing art talents in higher vocational colleges, each student should adjust the talent training objectives and training programs according to the national tourism industry guidance and the needs of the tourism market before training. The training of tourism 
performing art talents under the integration of culture and tourism still has a long way to go, and this paper also has many deficiencies. The author will continue to conduct in-depth research later especially on the creativity and accuracy in the process of cultural mining, so as to adapt to the new development and requirements of cultural tourism integration

\section{References}

[1] Baidu Encyclopedia. (2021, January 27). Performing Arts. http://baike.baidu.com/view/820545.htm

[2] Ding, Q. (2018). On Contemporary Dance Education Reform and Creative Talent Training Management in Colleges and Universities. China Commerce and Trade Press.

[3] Li, G. H. (2019). On Endogenous Dynamic Mechanism of Redevelopment of Tourism Performing Art Industry: Taking Guilin as Example. Journal of Huaihua University, 38(3), 61-66. https://doi.org/10.16074/j.cnki.cn43-1394/z.2019.03.012

[4] Liang, Y. K. (2012). On Operation Safety Guarantee System of Large-scale Live Tourism Performing Art Projects [Master's Huaqiao thesis, University]. https://kns.cnki.net/KCMS/detail/detail.aspx?dbname=CMFD201301\&filename $=1013000834 . n h$

[5] Pan, T. (2018). On the Industrialization of Tourism Performing Arts in China [Doctoral Dissertation, Shanghai Theatre Academy].

CNKI.

https://kns.cnki.net/KCMS/detail/detail.aspx?dbname=CDFDLAST2018\&filename=1018175173.nh

[6] Quan, H. (2018). On the Integration of Culture and Tourism in Tourism Performing Arts. Arts Criticism, (12), 14-18. https://doi.org/10.16364/j.cnki.cn11-4907/j.2018.12.003

[7] Song, R. (2019). How to Truly Realize Integrated Development of Culture and Tourism. Frontiers, (11), 24-35.

[8] Yuan, Y. (2013). On Training Mode of Tourism Talents in China [Doctoral Dissertation, CASS]. Wangfang Data. https://d.wanfangdata.com.cn/thesis/Y2513912

[9] Zeng, X. Y. (2018). On Construction of China's Tourism Talent Team under the Background of Global Tourism. Modern Education Management, (4), 185-186.

[10] Zhang, X. Z. (2020). On Contemporary Higher Dance Education Reform and Talent Training. China Book Press.

[11] Zhou, C. B. (2018). Integration Power of Cultural Industry and Tourism Industry: Theory and Demonstration. Enterprise Economy, 37(08), 146-151.

[12] Zhu, H. Y. (2019). On Construction Path of Training Mode of Dance Choreographers in Colleges and Universities. Art Education, (6), 86-87. 